\title{
IMAGING EVALUATION OF TRIGEMINAL NEURALGIA
}

\section{Trigeminal Nevraljide Görüntüleme}

\author{
Marinos KONTZIALIS, Mehmet KOÇAK
}

Received: 22/02/2017

Accepted:21/03/2017

\section{ABSTRACT}

Trigeminal neuralgia is a debilitating pain syndrome in the sensory distribution of the trigeminal nerve. Compression of the cisternal segment of the trigeminal nerve by a vessel, usually an artery, is considered the most common cause of trigeminal neuralgia. A number of additional lesions may affect the trigeminal nerve anywhere along its course from the trigeminal nuclei to the most peripheral branches to cause facial pain. Relevant differential considerations are reviewed starting proximally at the level of the brainstem.

Keywords: Trigeminal neuralgia; magnetic resonance imaging; neurovascular conflict; facial pain; brainstem

\section{$\ddot{O} Z$}

Trigeminal nevralji, trigeminal sinirin duyusal dă̆ıllmında görülen aşırı ağrllı bir sendromdur. Trigeminal nevraljinin ortaya çıkmasına sebep olan en önemli etkenin, bir damartn, genellikle de bir arterin, trigeminal sinirin sisternal segmentine basısı olduğu düsünülmektedir. Trigeminal sinirin nukleuslardan en uç dallara kadar uzanan trajesi boyunca herhangi bir bölgede meydana gelebilecek lezyonlar bu yüz ăgrisina neden olabilirler. Bu makalenin amacı beyin sapindan distale ilerleyerek bu lezyonların manyetik rezonans görüntüleme yöntemi ile elde edilen bulgularını değerlendirmektir.

Anahtar kelimeler: Trigeminal nevralji; manyetik rezonans görüntüleme; nörovasküler bası; yüz ağrısı; beyin sapt

Department of Radiology, Rush University Medical Center, Chicago, IL, USA

How to cite: Kontzialis M, Kocak M. Imaging evaluation of trigeminal neuralgia. J Istanb Univ Fac Dent 2017;51(3 Suppl 1):S62-S68. 
Kontzialis $M \& \operatorname{Koçak} M$

\section{Introduction}

Classic trigeminal neuralgia (TN) is an episodic stabbing facial pain syndrome followed by a period of relief in the sensory distribution of the trigeminal nerve (cranial nerve V; CN V). The pain may be triggered by mild sensory stimulation such as light touch, washing, cleaning teeth and shaving; and it can disrupt daily living and lead to depression (1). The anatomy of $\mathrm{CN} V$ will be briefly reviewed followed by a discussion on commonly implicated conditions in TN (Table 1).

Table 1. Causes of trigeminal neuralgia by location. The list is not exhaustive and highlights the major considerations encountered in clinical practice.

\begin{tabular}{|c|c|}
\hline Brainstem & Multiple sclerosis \\
\hline & Mass lesion: tumor, cavernous malformation \\
\hline & Infection including herpes \\
\hline & Infarct \\
\hline & Syringobulbia \\
\hline \multirow[t]{5}{*}{ Cisternal space and Meckel's cave } & Neurovascular conflict (the most common cause of trigeminal neuralgia) \\
\hline & Mass in the cisterns: schwannoma, meningioma, epidermoid \\
\hline & Leptomeningeal process: carcinomatosis, lymphoma, leukemia, sarcoidosis, meningitis \\
\hline & Skull base mass: chordoma, chondrosarcoma, multiple myeloma, osseous metastasis \\
\hline & Gradenigo syndrome \\
\hline \multirow[t]{4}{*}{ Cavernous sinus } & $\begin{array}{c}\text { Neoplasms: schwannoma, meningioma, pituitary macroadenoma, lymphoma, nasopharyngeal carcinoma, } \\
\text { metastatic disease }\end{array}$ \\
\hline & Tolosa-Hunt syndrome \\
\hline & Infection \\
\hline & Carotid-cavernous aneurysm/fistula \\
\hline \multirow[t]{2}{*}{ Extracranial space } & Perineural spread of head and neck neoplasm \\
\hline & Peripheral nerve sheath tumor \\
\hline
\end{tabular}

\section{Anatomy of the fifth cranial nerve}

$\mathrm{CN} \mathrm{V}$ is the largest cranial nerve and it has a mixed sensory and motor function (2). In the brainstem, there are three sensory and one motor trigeminal nuclei $(2,3)$. The mesencephalic nucleus mediates facial proprioception. In the pons, approximately at the level of the cisternal segment of $\mathrm{CN} \mathrm{V}$, the primary sensory nucleus mediates facial tactile sensation, and the motor nucleus innervates the muscles of the first branchial arch (Figure 1) (2). The spinal nucleus of CN V mediates facial pain and temperature, and is the largest nucleus extending from the dorsal aspect of the pons into the upper cervical cord. The cisternal segment of $\mathrm{CN}$ $\mathrm{V}$ arises from the anterolateral aspect of the pons (Figure 1), and consists of a large sensory root comprising the main bulk of the nerve, and of one or more smaller motor roots arising superomedial to the sensory root (4). The cisternal segment of CN V crosses the cisternal space and enters the Meckel's cave through the porus trigeminus (Figure 1). The trigeminal (or semilunar or gasserian) ganglion is centered along the anterior, inferior and lateral wall of the Meckel's cave, which is essentially a cerebrospinal fluid (CSF) filled space continuous with the subarachnoid space of the basal cisterns through the porus trigeminus (5). The ophthalmic (V1) and the maxillary division (V2) of CN V enter the cavernous sinus anterior to the Meckel's cave, whereas the mandibular divisions (V3) of CN V extends inferolateral to exit the skull base through the foramen ovale without entering the cavernous sinus (2). V1 courses along the lateral wall of the cavernous sinus and enters the orbit through the superior orbital fissure. V2 is also situated along the lateral wall of the cavernous sinus inferior to V1, and exits the skull base through the foramen rotundum to enter the pterygopalatine fossa. V3 never enters the cavernous sinus, but instead courses through foramen ovale to extend into the masticator space. V1, V2, and V3 supply sensory innervation to the upper, mid, and lower third of the face, respectively (2). CN V provides motor innervation to the muscles of mastication (medial and lateral pterygoid, masseter, and temporalis muscles), the mylohyoid, the anterior belly of the digastric, the tensor veli palatini, and the tensor tympani muscles.

\section{Neurovascular conflict}

Classic TN is most commonly secondary to neurovascular conflict (80-90\%), which refers to symptomatic compression of the cisternal segment of CN V by an artery or less commonly a vein (6). Neurovascular conflict can range from simple contact to severe compression, displacement and nerve volume loss (Figure 2) (7). The most common offending vessel is the superior cerebellar artery followed by the anterior and inferior cerebellar artery (6). Neurovascular contact is common in asymptomatic patients and in the 
asymptomatic side; and neurovascular contact alone cannot be used for diagnosis of TN without the appropriate clinical context (8). Symptomatic neurovascular conflict tends to involve the proximal half of the cisternal segment of CN V (9), and to produce nerve root displacement and atrophy (6). However, in a large series of patients that underwent microvascular decompression, neurovascular conflict was observed throughtout the cisternal segment of CN V (10). Furthermore, in a small series of TN due to venous compression, the offending vein was more common in the midcisternal segment and the porus trigeminus (11).

In our practice, when a patient presents for MRI with documented $\mathrm{TN}$ by clinical history and evaluation, any neurovascular contact or compression, arterial or venous, proximal or distal, is included in the final radiologic report along with morphologic alterations of the nerve (i.e., deformity, atrophy). The cisternal segment of $\mathrm{CN} \mathrm{V}$ is evaluated best with high-resolution three dimensional heavily T2-weighted sequences, such as constructive interference in steady state (CISS), and fast imaging employing steady-state acquisition (FIESTA) $(7,12)$. Less common causes of $\mathrm{TN}$ caused by vascular compression of the cisternal segment of CN V include saccular aneurysm, arteriovenous malformation, vertebrobasilar dolichoectasia, dural arteriovenous fistula, and persistent trigeminal artery (1-3).

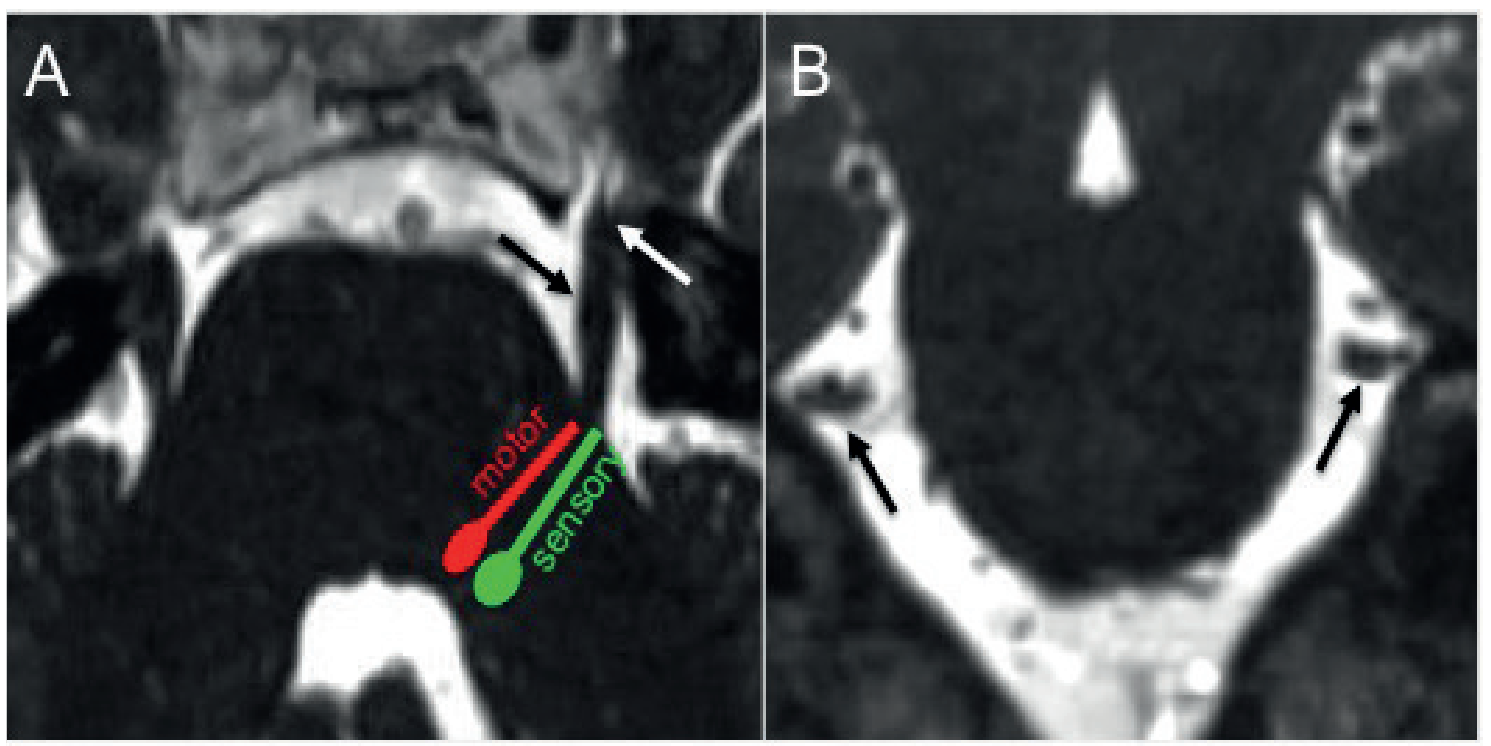

Figure 1. (a) Axial CISS image demonstrates the approximate location of the pontine trigeminal nuclei with their fibers projecting towards the anterolateral aspect of the pons to form the cisternal segment of $C N V$ (black arrow), which extends anteriorly to enter the Meckel's cave through the porus trigeminus (white arrow). (b) Coronal CISS image shows the cisternal segment of CN bilaterally in cross section (black arrows). Coronal reconstructions are helpful for evaluation of neurovascular conflict.

\section{Other causes of TN}

Evaluation of patients with TN with MRI for the presence of neurovascular conflict allows simultaneous evaluation for other causes $(6,7)$. A number of lesions occurring anywhere from the trigeminal nuclei to the most distal branches can cause facial pain (9), and relevant differential considerations are going to be reviewed starting proximally at the level of the brainstem.

\section{Brainstem}

Multiple sclerosis (MS) is the most common cause of trigeminal neuropathy in the brainstem (Figure 3A) (3). MS patients have a 20-fold increased risk for TN compared to the general population (13). Demyelinating plaques may involve the trigeminal nuclei, the fascicular fibers in the brainstem, or extend into the root entry zone of the cisternal segment (7). However, it should be kept in mind that neurovascular conflict may be the cause of pain in MS, and selected MS patients may benefit from microvascular decompression to separate the offending vessel from the cisternal segment of CN V (14). Various mass lesions in the brainstem, such as primary and metastatic tumors, and cavernous malformations (Figure 3B), may involve the nuclei and/or the fascicular fibers of $\mathrm{CN} \mathrm{V}(2,15)$. A cavernous malformation may cause isolated $\mathrm{TN}$, whereas neoplasms tend to produce more complex neurologic syndromes including long fiber tract and additional cranial nerve involvement (Figure 3C) (2). Cavernous malformations have a typical imaging appearance on MR due to blood degradation products that usually allows for a confident diagnosis (12). Infection involving the brainstem is called rhombencephalitis, and it may affect the trigeminal nuclei. Common pathogens include viruses, fungi, and Listeria $(2,12)$. In herpetic neuralgia, there is centripetal transaxonal spread of the virus along $\mathrm{CN} \mathrm{V}$ 
fibers to the brainstem nuclei (16). Hyperintense T2 signal may be observed involving the spinal trigeminal nucleus in trigeminal zoster (Figure 3D), Ramsay-Hunt syndrome, and in trigeminal neuropathy associated with herpes labialis (17). Transient enhancement of the cisternal segment of $\mathrm{CN}$ V has also been described in infectious neuritis (12).
Posterior inferior cerebellar artery infarcts may involve the spinal trigeminal nucleus. The most common presentation is lateral medullary/Wallenberg syndrome, which includes ipsilateral facial pain and temperature loss (3). Isolated trigeminal neuropathy due to infarct is uncommon (2).
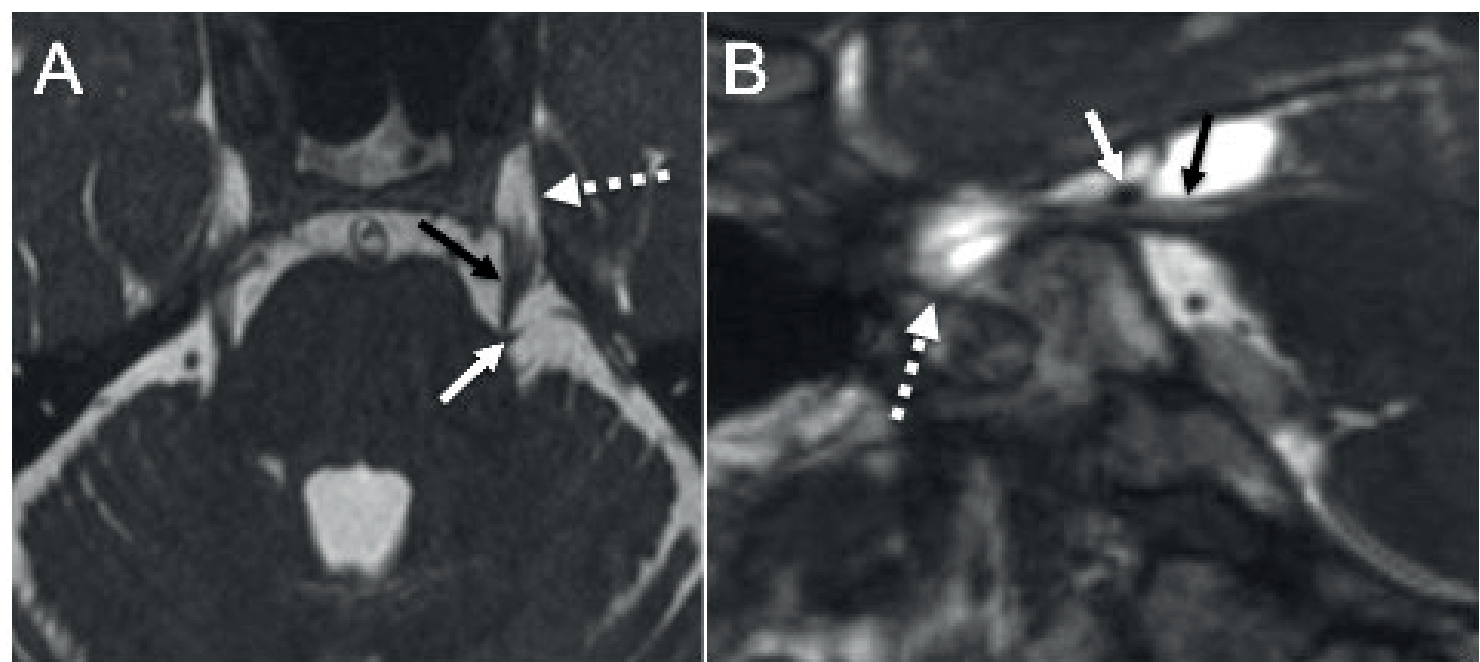

Figure 2. Neurovascular conflict causing TN. (a) Axial CISS image shows a vascular loop (white arrow), the left superior cerebellar artery, mildly deforming the root entry zone of the cisternal segment of the left CN V (black arrow). Note the cisternal segment bilaterally extending anteriorly to enter the Meckel's cave (dashed arrow), which is filled with CSF. (b) Sagittal CISS image along the long axis of the cisternal segment of the right $C N V$ (black arrow) shows the right superior cerebellar artery (white arrow) abutting the distal cisternal segment of the nerve near the porus trigeminus without deformity in a patient with right TN. The Meckel's cave (dashed arrow) is seen particularly well on this image anterior to the porus trigeminus.

\section{Cisternal space and Meckel's cave}

The cisternal segment of CN V may be involved, compressed and distorted by a wide variety of neoplasms and lesions $(3,12)$, which may present with TN accompanied by sensory loss (7). Trigeminal schwannomas are the most common primary neoplasm of $\mathrm{CN} \mathrm{V}$ and the second most common intracranial schwannoma following vestibular lesions (Figure 4A) (18). They may arise anywhere distal to the transitional zone in the cisternal segment, where the centrally myelinated portion of the nerve (oligodendrocytes) transitions to the peripherally myelinated portion of the nerve (Schwann cells) (9). Central myelination and thus the transitional zone may be located up to approximately the mid aspect of the cisternal segment of CN V (9). Schwannomas are benign nerve sheath tumors that may occur sporadically or in the setting of Neurofibromatosis type 2 (18). Most trigeminal schwannomas occur in the Meckel's cave (18), and tend to grow in the parasellar region or extend through the porus trigeminus in the posterior fossa along the cisternal segment of the nerve (15). Vestibular schwannomas may enlarge enough to cause TN $(1,12)$. Other common benign lesions in the skull base that may present with TN or trigeminal dysfunction include meningioma (Figure
4B) and epidermoid (Figure 4C). They may affect CN V in the cisternal space or the Meckel's cave $(2,15,19)$. TN, typical or atypical, was the presenting symptom in 10 out of 16 patients with Meckel's cave meningioma, and larger lesions tend to have additional cranial nerve deficits (20). $\mathrm{CN} \mathrm{V}$ in the cisternal space is susceptible to a number of a leptomeningeal processes, including carcinomatosis, lymphoma, leukemia, sarcoidosis, and meningitis $(3,12)$. Benign or malignant involvement of the cisternal segment of CN V presents with enhancement on imaging (Figure 4D), and the nerve itself may be enlarged (12). Skull base lesions, such as chordoma, chondrosarcoma, multiple myeloma and bony metastases, may grow exophytically in the basal cisterns to impinge on the nerve or may invade the Meckel's cave directly (2). Tumoral involvement of the Meckel's cave is well demonstrated on T2-weighted images due to effacement of the normal fluid intensity signal due to CSF (15), and mass-like enhancement confirms neoplastic tissue. Skull base osteomyelitis in the petrous apex may extend into the adjacent Meckel's cave to produce TN (Figure 5A). The classic Gradenigo syndrome triad is completed with the addition of diplopia due to involvement of the abducens nerve in the Dorello canal in the petroclival region and deafness due to concurrent suppurative otitis media $(2,21)$. 


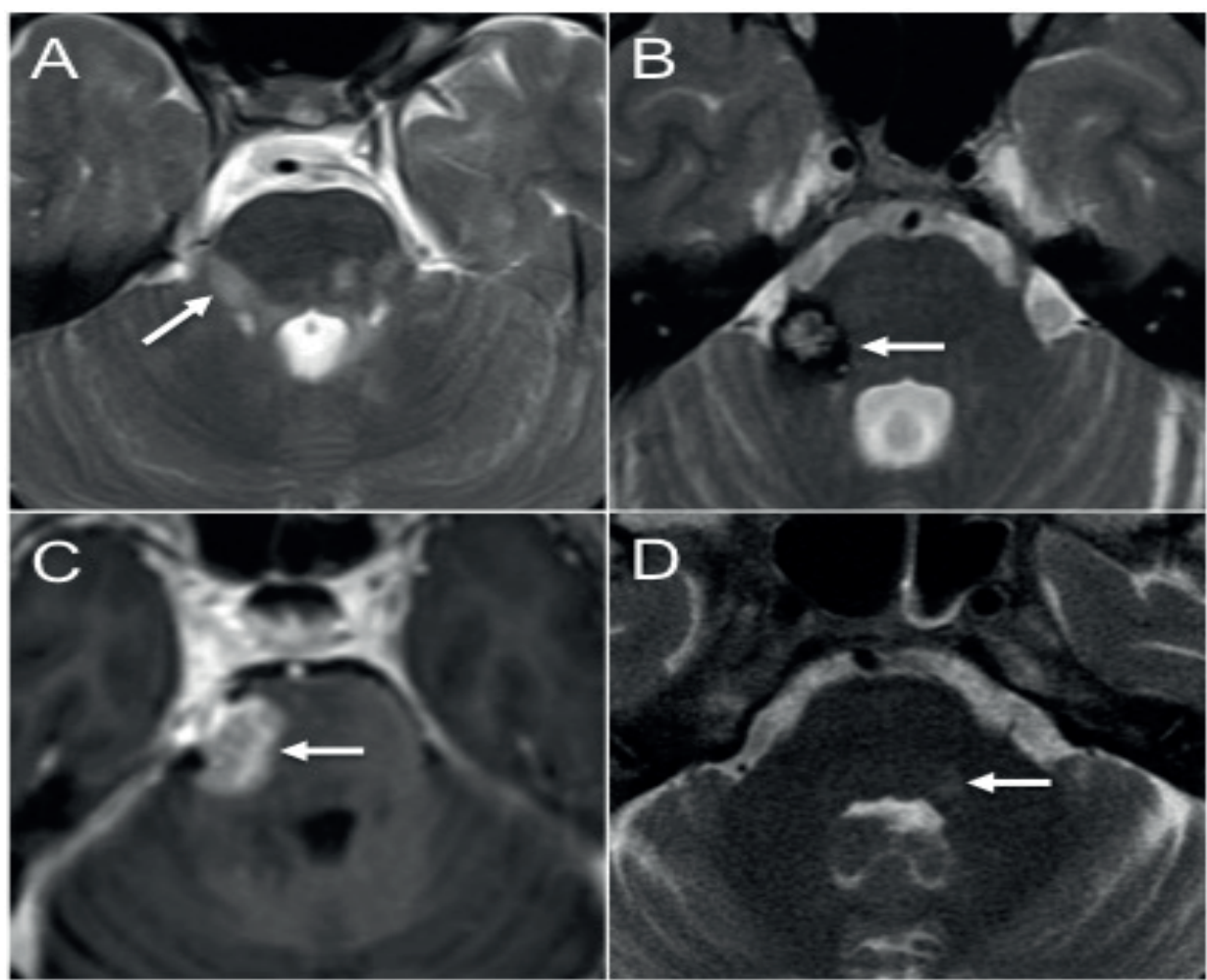

Figure 3. Brainstem lesions causing TN. (a) Axial T2-weighted image through the brainstem demonstrates multiple hyperintense lesions in the posterior fossa in MS including a lesion extending along the expected course of the fascicular fibers and towards the root entry zone of the right $C N V$ (arrow). (b) Axial T2-weighted image through the brainstem shows a characteristic cavernous malformation with central hyperintesities and surrounding hypointense hemosiderin rim (arrow). The lesion is centered in the right side of the pons extending towards the root entry zone of the right $C N V$. The patient presented with right-sided TN. (c) Axial postcontrast Tl-weighted image shows abnormal enhancing lesion extending from the right side of the pons (arrow) into the cisternal segment of the right $C N$ $V$. Biopsy revealed primary CNS lymphoma. (d) Axial T2-weighted image through the pons shows asymmetric subtle hyperintense signal along the cranial end of the trigeminal nucleus of $C N V$ (arrow). The patient presented with left facial shingles and pain, and was diagnosed with trigeminal zoster.

\section{Cavernous sinus}

Trigeminal schwannomas in the cavernous sinus usually arise in the Meckel's cave and demonstrate secondary anterior extension (2). Additional neoplastic considerations in the cavernous sinus leading to trigeminal neuropathy include meningioma, pituitary macroadenoma (Figure 5B), lymphoma, nasopharyngeal carcinoma (Figure 5C) and metastatic disease $(2,12,21)$. Tolosa-Hunt syndrome (THS) is an idiopathic inflammatory syndrome specific to the cavernous sinus and the orbital apex leading to painful ophthalmoplegia (21); and trigeminal branches may be involved. Typical imaging findings in THS include T2 hypointense signal and homogeneous intense enhancement. Vascular lesions that may involve the cranial nerves III, IV, VI, V1 and V2 in the cavernous sinus include cavernous carotid aneurysm and carotid cavernous fistula $(2,12)$. Trigeminal symptoms are present in approximately one third of these patients (3). Infection may spread from the paranasal sinuses intracranially into the cavernous sinus, and the typical scenario involves an immunosuppressed host including diabetic patients (12).

\section{Extracranial space}

The most common extracranial cause of trigeminal neuropathy is perineural spread of head and neck malignancies $(2,15)$. Commonly implicated lesions in perineural spread include squamous cell carcinoma, adenoid cystic carcinoma, lymphoma, melanoma, and sarcoma (22). The abnormal enhancement may track along the extracranial trigeminal divisions intracranially to involve the cavernous sinus (Figure 5D), the Meckel's cave, the cisternal segment of CN V, and rarely the brainstem (7). Nerve sheath tumors may arise from the extracranial branches of $\mathrm{CN} \mathrm{V}$, but are uncommon comprising only $5 \%$ of trigeminal schwannomas (2). 

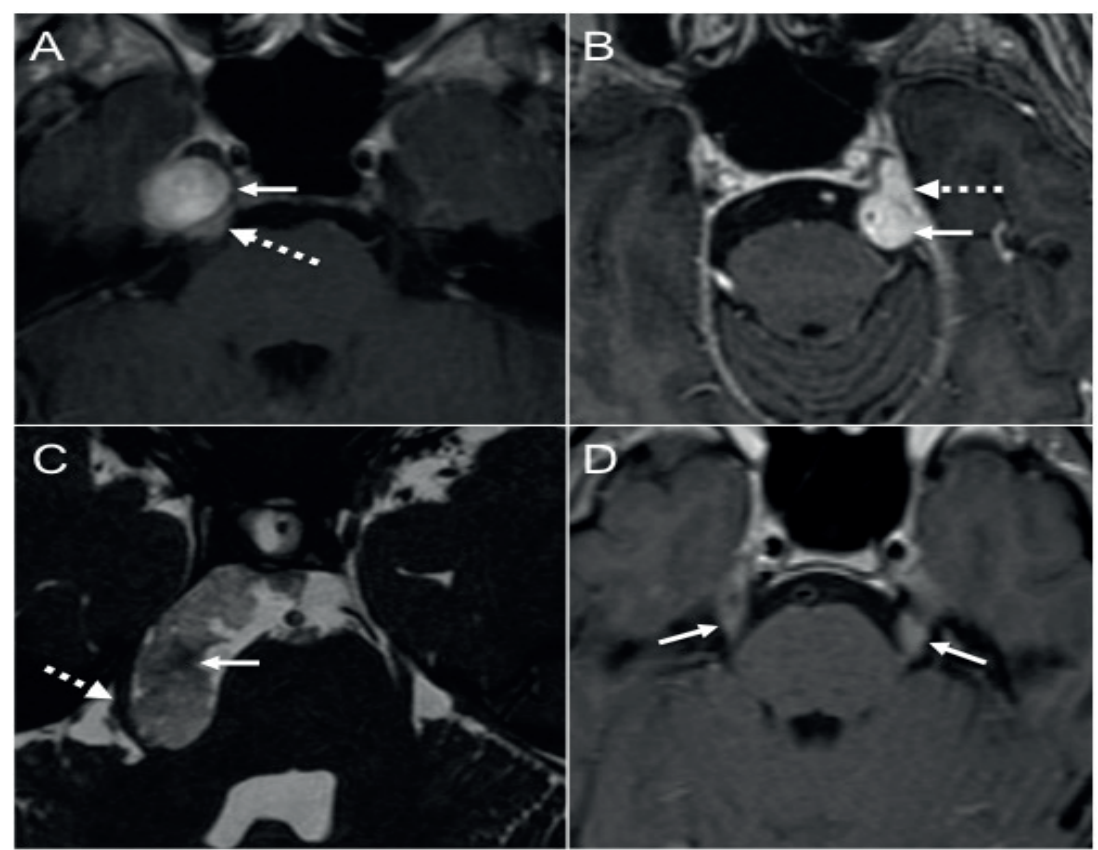

Figure 4. Lesions in the cisternal space and the Meckel's cave causing TN. (a) Axial postcontrast T1-weighted image demonstrates a round enhancing Schwannoma (arrow) centered in the right Meckel's cave with mild posterior extension through the porus trigeminus (dashed arrow). (b) Axial postcontrast T1-weighted image shows an avidly enhancing lesion in the left basal cisterns (arrow) with anterior extension into the left Meckel's cave (dashed arrow). The lesion was dural based arising from the dorsal left petroclival region, a biopsy proven meningioma. It was deforming the cisternal segment of the left CN V. (c) Axial CISS image shows obvious deformity of the cisternal segment of the right $C N V$ (dashed arrow) caused by an epidermoid (arrow). The epidermoid demonstrated restricted diffusion on diffusion weighted imaging (not shown). (d) Axial postcontrast T1-weighted image through the brainstem shows bilateral smooth enhancement along the cisternal segment of $C N V$ (arrows) in a patient with acute lymphoblastic leukemia. Additional cranial nerve enhancement was present (not shown).

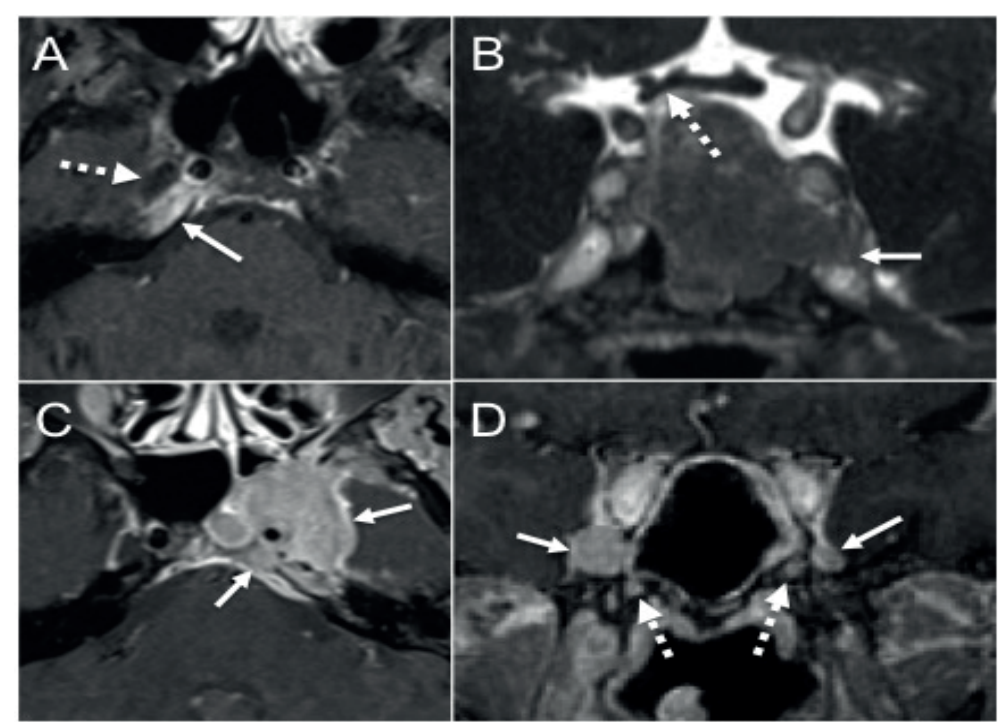

Figure 5. Skull base and cavernous sinus lesions. (a) Axial fat-suppressed post-contrast T1-weighted image shows asymmetric enhancement in the right petrous apex (arrow) immediately posterior to the right Meckel's cave (dashed arrow). This diabetic patient with petrous apicitis presented with right facial pain and right abducens nerve palsy. (b) Coronal postcontrast CISS image through the pituitary gland shows a large pituitary macroadenoma that infiltrates the left proximal cavernous sinus and the superior aspect of the left Meckel's cave with effacement of its normal fluid signal (arrow). The lesion superiorly abuts and mildly deforms the right side of the optic chiasm (dashed arrow). (c) Axial fatsuppressed T1-weighted image shows a large enhancing mass (arrows) that infiltrates the left petroclival region, the left Meckel's cave, and the left cavernous sinus. This was a large nasopharyngeal carcinoma with contiguous intracranial extension (d) Coronal postcontrast Tl-weighted image shows abnormal enlargement and enhancement of bilateral $V 2$ in the anterior cavernous sinus worse on the right (arrows) due to perineural spread from a large sinonasal adenoid cystic carcinoma. There is abnormal enhancement in bilateral vidian canals as well (dashed arrows). 


\section{Conclusion}

$\mathrm{TN}$ is a clinical diagnosis, and the most common cause is neurovascular conflict affecting the cisternal segment of CN V. MRI is helpful to confirm neurovascular contact when present and to exclude other causes, which may occur anywhere from the brainstem to the extracranial space.

\section{Source of funding}

None declared.

\section{Conflict of interest}

None declared.

\section{References}

1. Love S, Coakham HB. Trigeminal neuralgia: Pathology and pathogenesis. Brain 2001;124(Pt 12):2347-2360.

2. Borges A, Casselman J. Imaging the trigeminal nerve. Eur J Radiol 2010;74(2):323-340

3. Bathla G, Hegde AN. The trigeminal nerve: An illustrated review of its imaging anatomy and pathology. Clin Radiol 2013;68(2):203-213.

4. Yousry I, Moriggl B, Holtmannspoetter M, Schmid UD, Naidich TP, Yousry TA. Detailed anatomy of the motor and sensory roots of the trigeminal nerve and their neurovascular relationships: A magnetic resonance imaging study. J Neurosurg 2004;101(3):427-434.

5. Yousry I, Moriggl B, Schmid UD, Naidich TP, Yousry TA. Trigeminal ganglion and its divisions: Detailed anatomic $\mathrm{mr}$ imaging with contrast-enhanced $3 \mathrm{~d}$ constructive interference in the steady state sequences. AJNR Am J Neuroradiol 2005;26(5):1128-1135.

6. Donahue JH, Ornan DA, Mukherjee S. Imaging of vascular compression syndromes. Radiol Clin North Am 2017;55(1):123-138.

7. Seeburg DP, Northcutt B, Aygun N, Blitz AM. The role of imaging for trigeminal neuralgia: A segmental approach to high-resolution mri. Neurosurg Clin N Am 2016;27(3):315-326.

8. Panczykowski DM, Frederickson AM, Hughes MA, Oskin JE, Stevens DR, Sekula RF, Jr. A blinded, case-control trial assessing the value of steady state free precession magnetic resonance imaging in the diagnosis of trigeminal neuralgia. World Neurosurg 2016;89(427-433.

9. Hughes MA, Frederickson AM, Branstetter BF, Zhu X, Sekula RF, Jr. Mri of the trigeminal nerve in patients with trigeminal neuralgia secondary to vascular compression. AJR Am J Roentgenol 2016;206(3):595-600.

10. Sindou M, Howeidy T, Acevedo G. Anatomical observations during microvascular decompression for idiopathic trigeminal neuralgia (with correlations between topography of pain and site of the neurovascular conflict). Prospective study in a series of 579 patients. Acta Neurochir (Wien) 2002;144(1):1-12; discussion 12-13.
11. Hong $\mathrm{W}$, Zheng $\mathrm{X}$, Wu Z, Li X, Wang X, Li Y, Zhang W, Zhong J, Hua X, Li S. Clinical features and surgical treatment of trigeminal neuralgia caused solely by venous compression. Acta Neurochir (Wien) 2011;153(5):1037-1042.

12. Becker M, Kohler R, Vargas MI, Viallon M, Delavelle J. Pathology of the trigeminal nerve. Neuroimaging Clin N Am 2008;18(2):283-307, x.

13. van Hecke O, Austin SK, Khan RA, Smith BH, Torrance N. Neuropathic pain in the general population: A systematic review of epidemiological studies. Pain 2014;155(4):654-662.

14. Prasad S, Galetta S. Trigeminal neuralgia: Historical notes and current concepts. Neurologist 2009;15(2):8794.

15. Majoie CB, Verbeeten B, Jr., Dol JA, Peeters FL. Trigeminal neuropathy: Evaluation with mr imaging. Radiographics 1995;15(4):795-811.

16. Hung CW, Wang SJ, Chen SP, Lirng JF, Fuh JL. Trigeminal herpes zoster and ramsay hunt syndrome with a lesion in the spinal trigeminal nucleus and tract. J Neurol 2010;257(6):1045-1046.

17. Kontzialis M, Zamora CA. Mri of trigeminal zoster. Arq Neuropsiquiatr 2015;73(11):976.

18. MacNally SP, Rutherford SA, Ramsden RT, Evans DG, King AT. Trigeminal schwannomas. Br J Neurosurg 2008;22(6):729-738.

19. Furtado SV, Hegde AS. Trigeminal neuralgia due to a small meckel's cave epidermoid tumor: Surgery using an extradural corridor. Skull Base 2009;19(5):353-357.

20. Delfini R, Innocenzi G, Ciappetta P, Domenicucci M, Cantore G. Meningiomas of meckel's cave. Neurosurgery 1992;31(6):1000-1006; discussion 1006-1007.

21. Kontzialis M, Choudhri AF, Patel VR, Subramanian PS, Ishii M, Gallia GL, Aygun N, Blitz AM. Highresolution $3 \mathrm{~d}$ magnetic resonance imaging of the sixth cranial nerve: Anatomic and pathologic considerations by segment. J Neuroophthalmol 2015;35(4):412-425.

22. Kontzialis M, Glastonbury CM, Aygun N. Evaluation: Imaging studies. Adv Otorhinolaryngol 2016;78(2538.

\author{
Corresponding Author: \\ Marinos KONTZIALIS \\ Department of Radiology \\ Rush University Medical Center \\ 1653 W Congress Pkwy, Chicago, IL 60612, \\ USA \\ Phone: +1 3129470398 \\ e-mail: marinos.kontzialis@gmail.com
}

